\title{
Vancomycin Intermediate MRSA Isolates Obtained from Retail Chicken Meat and Eggs Collected at Pokhara, Nepal
}

\author{
Surya Prasad Devkota 1, 2,3*, Ashmita Paudel ${ }^{3}$, Krishna Gurung 1, 4 \\ 1Pokhara Bigyan Tatha Prabidhi Campus, Nayabazzar, Pokhara \\ ${ }^{2}$ School of Health and Allied Sciences, Pokhara University \\ ${ }^{3}$ Regional College of Health Science and Technology, Nayabazzar, Pokhara \\ 4 Prithvi Narayan Campus, Pokhara
}

\begin{abstract}
Antimicrobial resistance among food animal isolates is increasing as a result of their uncontrolled uses. The monitoring of antibiotic resistance among these isolates is very necessary. $S$ aureus was isolated from eggshells and chicken meat samples collected from different retail outlets of the Pokhara metropolitan. Samples were inoculated on Mannitol salt agar aseptically and inoculated overnight. Isolated yellow colonies were further examined by Gram-staining, catalase, and coagulase test to detect $S$ aureus. Methicillin resistance was screened using cefoxitin disc. Vancomycin minimum inhibitory concentration (MIC) of Methicillin-resistant $S$ aureus (MRSA) isolates were determined by the agar dilution method following CLSI guidelines. $139 \mathrm{~S}$ aureus were isolated from 205 samples. Among them, 89 were from egg samples (out of 125 samples) and 50 from chicken (out of 80 samples). The overall prevalence of MRSA was 12.94\%. Antibiotic resistance was significantly higher in MRSA isolates compared to Methicillin sensitive $S$ aureus (MSSA) isolates. The highest rate of resistance was noted for ampicillin, amoxicillin, and erythromycin while the least resistance was noted for gentamicin and amikacin. Vancomycin minimum inhibitory concentration (MIC) range of the MRSA isolates was $0.25-8 \mu \mathrm{g} / \mathrm{ml}$ indicating the detection of both vancomycin-intermediate and sensitive isolates from the samples. This is the first study reporting vancomycin-intermediate $S$ aureus (VISA) isolates from Nepal and indicates the increasing drug resistance among animal isolates. Further surveillance studies about the transmission of these pathogens to humans as well as detail molecular analyses are imminent.
\end{abstract}

Keywords: MRSA, vancomycin-intermediate, $S$ aureus, eggs, meat

*Corresponding Author

Email: devkotasp1@gmail.com

\section{Introduction}

Staphylococcus aureus is a significant pathogen that causes diseases both in humans and animals and their treatment is gradually becoming difficult due to their increasing resistance to antimicrobial agents [1]. Dry resistance properties of the organism assist them to thrive in adverse environmental conditions including various food items, human skin, nose and other inanimate objects for a longer period [2]. The presence of these organisms in animals has started gaining importance these days as they are the cause of increasing livestock infections and their ability to cause zoonotic infections [3]. Staphylococcus associated with animals may be hazardous to humans not only due to their antibiotic resistance but also as the causative agents of food-related infections [4]. The presence of drug-resistant bacteria in meat is a significant public health challenge and the incidence of resistance has risen in this decade among pathogens that are transmitted via food [5]. Methicillin-resistant S. aureus (MRSA) has been detected from various animals used for food production and from animal-related food items including milk, meat, and dairy products which necessitate the targeted researches to determine the prevalence of these isolates in food to assess the probable risk of these foods as sources for human infection [6]. In addition to two common types of MRSA i.e community-associated MRSA and hospital-associated MRSA, a third form of MRSA known as livestock-associated MRSA has now emerged which infects various animals [7]. 
There is the possibility of transmission of MRSA isolates associated with livestock not only between animals and humans but also between humans [8].

There are reports of decreasing vancomycin sensitivity among $S$ aureus isolated in Nepal in recent times [9]. The study of Adhikari et al have reported that vancomycin MIC range for $S$ aureus isolated from pus samples was $0.016 \mu \mathrm{g} / \mathrm{ml}$ to $1 \mu \mathrm{g} / \mathrm{ml}[10]$. Very recently, vancomycin-resistant and vancomycin-intermediate $S$ aureus have been isolated from clinical samples [11]. Many studies have reported that all clinical $S$ aureus isolates from Nepal were absolutely sensitive to vancomycin [12, 13]. However, there have not been any studies that focus on vancomycin MIC value of $S$ aureus isolated from non-clinical samples including food animals, food samples, and environmental samples in Nepal.

There is a huge and uncontrolled use of antibiotics in animal farms in Nepal. This might have led to the development of resistance among animal isolates. In this study, we particularly focused on S. aureus isolates as they are one of the frequent isolates from eggs and meat samples. However, there are no studies about the effects of this unscientific use of antibiotics on these animal isolates. This is the first study focusing on vancomycin MIC values of MRSA isolates obtained from these samples in this region and the country as well.

\section{Materials and methods Samples}

Chicken eggs and chicken meat samples were collected in sterile zipped plastic bags from different retail outlets of Pokhara Metropolitan from January to February and July to August 2019. The number of samples collected was 125 and 80 respectively for eggs and chicken meat.

\section{Sample processing}

Eggshells were swabbed thoroughly using the sterile cotton swabs moistened with sterile nutrient broth and inoculated on Mannitol salt agar using aseptic technique. Similarly, 5 grams of each meat sample was transferred to $50 \mathrm{ml}$ of sterile nutrient broth in a sterile environment and incubated overnight. Then one loopful of the broth was inoculated on mannitol salt agar aseptically. Sterile forceps, mask, and gloves were used during sample processing to prevent contamination during the procedure. The inoculated plates were then incubated at $37^{\circ} \mathrm{C}$ for 18-24 hrs.

\section{Identification of $S$ aureus}

After incubation, the mannitol salt agar plates were observed for yellow colonies. Isolated yellow colonies on mannitol salt agar were further tested using Gram-staining, catalase test, oxidase test, and coagulase test. Gram-positive cocci in a cluster that was catalase-positive, coagulase-positive were confirmed as $S$ aureus as reported earlier [4].

\section{AST of $S$, aureus isolates and MRSA screening}

Kirby Bauer disc diffusion method was used to study the antimicrobial susceptibility pattern of the $S$. aureus isolates as per CLSI guidelines [14]. Antibiotics used were amikacin $(30 \mu \mathrm{g})$, ciprofloxacin $(5 \mu \mathrm{g}), \quad$ ampicillin $(10 \mu \mathrm{g})$, amoxycillin $(10 \mu \mathrm{g}), \quad$ gentamicin $(10 \mu \mathrm{g})$, erythromycin $(15 \mu \mathrm{g})$, and cefoxitin $(30 \mu \mathrm{g})$. Cefoxitin was used for the screening of MRSA isolates. Isolates with a zone of inhibition $21 \mathrm{~mm}$ or less were confirmed as MRSA isolates as per CLSI guidelines [14]. MRSA isolates were preserved using glycerol stock preparation and by stabbing on semi-solid media for vancomycin MIC detection.

\section{Vancomycin MIC detection}

The agar dilution method was used to detect MIC of the isolates. $526 \mathrm{mg}$ of vancomycin powder (Hi-Media, India with potency $950 \mu \mathrm{g} / \mathrm{mg}$ ) was dissolved in $10 \mathrm{ml}$ sterile distilled water to prepare the stock solution $(50 \mathrm{mg} / \mathrm{ml})$. Then tenfold dilutions (two times) of the stock were prepared to prepare working solutions having a concentration of $0.5 \mathrm{mg} / \mathrm{ml}$. From the working solution, further dilutions were made on Brain heart infusion agar. Various dilutions of vancomycin prepared were $0.25 \mu \mathrm{g} / \mathrm{ml}$, $0.5 \mu \mathrm{g} / \mathrm{ml}, 1 \mu \mathrm{g} / \mathrm{ml}, 2 \mu \mathrm{g} / \mathrm{ml}, 4 \mu \mathrm{g} / \mathrm{ml}, 8 \mu \mathrm{g} / \mathrm{ml}$, $16 \mu \mathrm{g} / \mathrm{ml}$, and $32 \mu \mathrm{g} / \mathrm{ml}$ as reported earlier [15]. Staphylococcus aureus ATCC 25923 was used as a negative control. 
Mac-Farland standard (0.5) suspension of each test isolates was prepared by mixing one or two isolated colonies on blood agar. Each isolate was then inoculated on Brain heart infusion agar containing various dilutions of vancomycin and incubated at $37^{\circ} \mathrm{C}$ for 24 hours and observed for presence or absence of growth as indicated earlier [16]. Lowest dilution of vancomycin preventing notable growth was considered as the MIC value for that isolate. Isolates were classified as vancomycin sensitive, intermediate, and resistant if the MIC value were $\leq 2 \mu \mathrm{g} / \mathrm{ml}$, 4$8 \mu \mathrm{g} / \mathrm{ml}$, and $\geq 16 \mu \mathrm{g} / \mathrm{ml}$ respectively based on CLSI guidelines [14].

\section{Results}

A total of 125 chicken eggs were processed during the study period. Among them, 50 were analyzed during winter and 75 during the summer season. Similarly, 80 meat samples were included for the study (35 in winter and 45 in summer). In winter isolation rate of $S$ aureus from eggs was $68 \%$ (34 from 50 samples). Only 2 isolates $(5.88 \%)$ were confirmed as MRSA. Likewise, in the same season, $21 S$ aureus was isolated from the meat sample. Among them, 5 $(23.8 \%)$ were confirmed as MRSA (Table 1).

Table 1. Prevalence of MRSA isolates from meat and egg samples

\begin{tabular}{|c|c|c|c|c|}
\hline $\begin{array}{l}\text { Study } \\
\text { period }\end{array}$ & Sample & Number & $\begin{array}{l}S \\
\text { aureus }\end{array}$ & $\begin{array}{l}\text { MRSA } \\
\text { No (\%) }\end{array}$ \\
\hline \multirow{2}{*}{$\begin{array}{l}\text { Jan- } \\
\text { Feb } \\
2019\end{array}$} & $\begin{array}{c}\text { Chicken } \\
\text { eggs }\end{array}$ & 50 & 34 & $\begin{array}{c}2 \\
(5.88 \%)\end{array}$ \\
\hline & Chicken & 35 & 21 & $\begin{array}{c}5 \\
(23.8 \%)\end{array}$ \\
\hline $\begin{array}{l}\text { Jul- } \\
\text { Aug }\end{array}$ & $\begin{array}{c}\text { Chicken } \\
\text { eggs }\end{array}$ & 75 & 55 & $\begin{array}{c}4 \\
(7.27 \%) \\
7\end{array}$ \\
\hline 2019 & Chicken & 45 & 29 & $(24.13 \%)$ \\
\hline
\end{tabular}

The prevalence of both $S$ aureus and MRSA was slightly higher in summer. During this period $73.33 \%$ of egg samples were positive for $S$ aureus. Only four $S$ aureus isolates (out of 55 total isolates) from egg were MRSA. Similarly, $64.44 \%$ of chicken samples yielded $S$ aureus. The incidence of MRSA was $24.13 \%$ in chicken $S$ aureus isolates (Table 1 ).

Both vancomycin sensitive and vancomycinintermediate MRSA isolates were detected both from egg and chicken samples. However, the MIC value was higher for meat isolates. MIC range of vancomycin for egg isolates was 0.25 to $4 \mu \mathrm{g} / \mathrm{ml}$. Similarly, the MIC range was 0.25 to $8 \mu \mathrm{g} / \mathrm{ml}$ for chicken isolates (Table 3). The majority of egg MRSA isolates were vancomycin sensitive while only 1 isolate $(16.6 \%)$ isolates were vancomycin-intermediate. $8(66.66 \%)$ of the chicken meat isolates were sensitive to vancomycin and the remaining 4(33.33\%) isolates were vancomycin-intermediate. This result indicates that there is reduced vancomycin susceptibility among MRSA isolates obtained from meat and egg. This increase in resistance may be either due to the direct use of vancomycin in animal farms or due to the use of similar antibiotics for various purposes. If we consume these food products without proper cooking they may cause infections that are difficult to treat. In addition to consumers, the workers working in slaughterhouse and retail meat shops are at high risk of acquiring these pathogens as they work there without proper safety measures. If the current practices of animal farming, processing, and distribution of meat and egg samples continue, vancomycin resistance may be observed in $S$ aureus isolates from these food items soon. Hence, all the concerned sectors should be converged to minimize the increasing drug-resistance among various food isolates.

Table 2: Resistance pattern of MRSA and MSSA isolates

\begin{tabular}{lcc}
\hline Antibiotics & $\begin{array}{c}\text { MRSA } \\
(\mathrm{N}=18)\end{array}$ & $\begin{array}{c}\text { MSSA } \\
(\mathrm{N}=121)\end{array}$ \\
\hline Ampicillin & $11(61.1 \%)$ & $21(17.3 \%)$ \\
Amoxycillin & $9(50 \%)$ & $19(15.7 \%)$ \\
& & \\
Amikacin & $7(38.8 \%)$ & $12(9.9 \%)$ \\
Gentamicin & $8(44.4 \%)$ & $11(9 \%)$ \\
Ciprofloxacin & $10(55.5 \%)$ & $13(10.7 \%)$ \\
Erythromycin & $10(55.5 \%)$ & $15(12.3 \%)$ \\
Co-trimoxazole & $9(50 \%)$ & $14(11.5 \%)$ \\
Cefoxitin & $18(100 \%)$ & $0(0 \%)$ \\
\hline
\end{tabular}

\section{Discussion}

Antibiotic resistance among animal and food animal isolates has been increasing throughout the world. This problem is more severe in developing countries due to the lack of proper monitoring of antibiotics use and the lack of awareness about the adverse effects of antibiotic 
Table 3: Vancomycin Minimum inhibitory concentration (MIC) values of MRSA isolates

\begin{tabular}{lccccccccc}
\hline Sample & $\begin{array}{c}\text { Total } \\
\text { isolates }\end{array}$ & $\begin{array}{c}0.25 \mu \mathrm{g} / \mathrm{ml} \\
\text { No }(\%)\end{array}$ & $\begin{array}{c}0.5 \mu \mathrm{g} / \mathrm{ml} \\
\text { No }(\%)\end{array}$ & $\begin{array}{c}1 \mu \mathrm{g} / \mathrm{ml} \\
\text { No }(\%)\end{array}$ & $\begin{array}{c}2 \mu \mathrm{g} / \mathrm{ml} \\
\text { No }(\%)\end{array}$ & $\begin{array}{c}4 \mu \mathrm{g} / \mathrm{ml} \\
\text { No }(\%)\end{array}$ & $\begin{array}{c}8 \mu \mathrm{g} / \mathrm{ml} \\
\text { No }(\%)\end{array}$ & $\begin{array}{c}16 \mu \mathrm{g} / \mathrm{ml} \\
\text { No }(\%)\end{array}$ & $\begin{array}{c}32 \mu \mathrm{g} / \mathrm{ml} \\
\text { No }(\%)\end{array}$ \\
\hline Egg & 6 & $1(16.6)$ & $1(16.6)$ & $2(33.3)$ & $1(16.6)$ & $1(16.6)$ & $0(0)$ & $0(0)$ & $0(0)$ \\
Meat & 12 & $1(8.33)$ & $2(16.6)$ & $3(25)$ & $2(16.6)$ & $2(16.6)$ & $2(16.6)$ & $0(0)$ & $0(0)$ \\
\hline
\end{tabular}

resistance. This problem is further complicated by the lack of proper hygiene during animal slaughter and the use of contaminated equipment and water during the processing of meat and eggs before sending it to the retail market. Hence this study was designed to monitor the antibiotic resistance pattern of MRSA and MSSA isolates obtained from meat and egg samples as well as to access the vancomycin MIC value of the MRSA isolates obtained from these samples.

The overall prevalence of $S$ aureus among egg and chicken samples was 59.02\% (121 out of 205 samples). Among the isolates, 89 were from eggs and the remaining 50 isolates were from meat samples. This result indicates gross contamination of these food products with $S$ aureus and is the indication of poor hygiene practices. The very similar isolation rate of $S$ aureus was reported in Nigeria from meat and other food items [17]. While the prevalence was significantly different in other studies [18, 19]. The prevalence of this bacteria varies based on geographic location and sanitation status. The average incidence of MRSA from both samples was $12.94 \%$ (6.74\% among egg isolates and $24 \%$ among chicken isolates). Almost identical incidence of MRSA was noted among chicken samples from Nigeria [20]. On the other hand, a low prevalence of MRSA was also noted from meat and other food items in China [21], and no MRSA isolates at all from meat, egg, and other food isolates in China [22] as indicated by the absence of mecA gene in all isolates. The prevalence of MRSA from various meat and other food samples was comparatively high in Algeria compared to this study [23].

Antibiotic resistance was quite high among MRSA isolates compared to MSSA isolates as the resistance range for the tested antibiotics was 9$17.3 \%$ for MSSA while the range was $38-61 \%$ for MRSA isolates. Resistance was high for ampicillin (61.1\%), ciprofloxacin (55.5\%), and erythromycin (55.5\%) while low for gentamicin

$(44.4 \%)$ and amikacin $(38.8 \%)$ for MRSA isolates.

One study from China [22] has shown increased drug resistance of $S$ aureus isolated from food items as these isolates were resistant to penicillin $(92.47 \%)$, erythromycin $(58.06 \%)$, and kanamycin (25.8\%). Another study has also reported elevated antibiotic resistance among $S$ aureus isolated from raw meat samples collected from various provinces of China where the resistance pattern was $83.7 \%$ for penicillin, $52.1 \%$ for erythromycin, and $17.4 \%$ for ciprofloxacin [24]. These findings are comparable with the resistance pattern of isolates obtained in the current study.

To the best of our knowledge, this is the first study reporting vancomycin MIC value of MRSA isolates obtained from food samples in Nepal. Similarly, this is the first report indicating the detection of vancomycin intermediate methicillin resistant $S$ aureus isolated from retail chicken meat and egg samples. Similar to the finding of this study various authors also have reported vancomycin-intermediate $S$ aureus from various food samples obtained from animals. Vancomycin intermediate isolates (MIC $8 \mu \mathrm{g} / \mathrm{ml}$ ) have been detected in India from milk samples [25]. Not only this, several reports are indicating the presence of vancomycin-resistant $S$ aureus (VRSA) isolates from various food samples. The study of Bhattacharyya et al [25] reported vancomycin-resistant Staphylococcus from milk samples. Likewise, VRSA isolates were reported from Egypt from diverse samples including minced meat, mastitis milk, and sausage samples with vancomycin MIC range of $64-1024 \mu \mathrm{g} / \mathrm{ml}$ [26]. VRSA also has been detected from camel meat and slaughterhouse workers in Egypt with a prevalence of $35 \%$ among $S$ aureus isolates [27]. Though vancomycin resistance was not detected in this study further studies are very necessary throughout the nation including more sample size and diverse samples as only large scale study can provide an actual picture of this problem. Timely surveillance of these pathogens is also 
necessary. Physician and microbiology labs should not completely rely on vancomycin disc test for the susceptibility of MRSA isolates and must determine the vancomycin MIC values before treatment. They should be updated with the recent susceptibility trend of these isolates of the particular locality as well.

\section{Conclusion}

This study reported the existence of vancomycinintermediate $S$ aureus isolates in Nepal and typically in Pokhara from meat and egg samples. Rise of vancomycin-intermediate $S$ aureus isolates among various food isolates is a serious concern as there is a possibility of transmission of these isolates to the consumers. Hence, further epidemiological and molecular analyses are needed to prevent their spread to humans. Similarly, the prudent use of antibiotics in animal farms is urgent.

\section{Limitations of the study}

Vancomycin MIC of the MSSA isolates couldn't be performed. Similarly, molecular analysis (mecA gene detection) of the MRSA isolates was not done due to limited laboratory facilities and economical constrain.

\section{Acknowledgment}

We are very thankful to Pokhara Bigyan Tatha Prabdhi Campus, Pokhara for allowing us to conduct this research in their laboratory and all the Microbiology lab staff for their continuous support.

\section{Funding}

This study was carried out without any financial support.

\section{Reference}

1. Sato T, Usui M, Konishi N, Kai A, Matsui H, Hanaki $\mathrm{H}$, et al: Closely related methicillinresistant Staphylococcus aureus isolates from retail meat, cows with mastitis, and humans in Japan. PLoS ONE. 2017 12(10): e0187319.

2. Kadariya J, Smith TC, Thapaliya D: Staphylococcus aureus and Staphylococcal Food-Borne Disease: An Ongoing Challenge in Public Health. BioMed Res Int. 2014 Article ID 827965, 9 pages

3. Lozano C, Gharsa H, Slama KB, Zarazaga M, Torres C: Staphylococcus aureus in Animals and Food: Methicillin Resistance, Prevalence and Population Structure. A Review in the
African Continent. Microorganisms. 2016, 4(1): 12.

4. Pondit A, Haque ZF, Al MSA, Khan SR, Saha S: Characterization of Staphylococcus aureus isolated from chicken and quail eggshell. J Adv Vet Anim Res. 2018 5(4): 466-471.

5. Ruban SW, Babu RN, Abraham RJJ, Senthilkumar TMA, Kumraswamy P,bRao VA: Prevalence of Methicillin Resistant Staphylococcus aureus in retail Buffalo meat in Chennai, India. Buffalo Bull. 2018 37(1): 51-58.

6. Sergelidis D, Abrahim A, Anagnostou V: Prevalence, Distribution, and Antimicrobial Susceptibility of Staphylococcus aureus in Ready-to-Eat Salads and in the Environment of a Salad Manufacturing Plant in Northern Greece. Czech J. Food Sci. 2012, 30(3): 285-291.

7. Chon J, Sung K, Khan S: Methicillinresistant Staphylococcus aureus (MRSA) in food-producing and companion animals and food products. Eds Enany S, Alexander LC In Frontiers in Staphylococcus aureus. 2017 48-101.

8. Fan Y, Li SM, Deng BG and Zhao YX: Prevalence and relevance analysis of multidrug-resistant Staphylococcus aureus of meat, poultry and human origin. Indian J Anim Res. 201549 (1): 8690.

9. Kshetry AO, Pant ND, Bhandari R, Khatri S, Shrestha KL, Upadhaya SK et al: Minimum inhibitory concentration of vancomycin to methicillin resistant Staphylococcus aureus isolated from different clinical samples at a tertiary care hospital in Nepal. Antimicrob Resist Infect Control. 2016 5:27.

10. Adhikari R, Pant ND, Neupane S, Neupane M, Bhattarai R, Bhatta $S$, et al: Detection of MRSA and determination of MIC concentration of vancomycin for $S$ aureus isolated fron pus/ wound swab samples of the patient attending a tertiary care hosprtal in Kathmandu, Nepal. Can J Infect Dis Med Microbiol. 2017 2017: 2191532.

11. Lama U, Shah D, Shrestha U: Vancomycin Resistant Staphylococcus aureus Reported from Tertiary Care Hospital in Nepal. TUJM. 2018, 4: 63-72.

12. Khanal LK, Adhikari RM, Guragain A: Prevalence of MRSA and Antibiotic susceptibility pattern in a tertiary care Hospital in Nepal. J Nepal Health Res Counc. 2018 16(2):172174.

13. Bhatta DR, Cavaco LM, Nath G, Gaur A, Gokhale S, Bhatta DR: Threat of multidrug resistant Staphylococcus aureus in Western Nepal. Asian Pac J Trop Dis. 2015 5(8): 617-21.

14. Clinical and Laboratory Standards Institute: Performance standards for antimicrobial susceptibility testing, twenty-second informational supplement, CLSI, Document M100 S27, CLSI, Wayne, Pa, USA, 2017.

15. Othman HB, Halim RMA, Gomaa FAM, Amer MZ: Vancomycin MIC distribution among Methicillin-Resistant Staphylococcus aureus. Is 
reduced vancomycin susceptibility related to MIC creep? Maced J Med Sci. 2018 7(1):12-18

16. Chaudhari CN, Tandel $K$, Grover N, Bhatt P, Sahni AK, Sen $S$, et al: In vitro vancomycin susceptibility amongst methicillin resistant Staphylococcus aureus. Med J Armed Forces India. 2014 70(3): 215-9.

17. Sokari T: Distribution of enterotoxigenic Staphylococcus aureus in ready-to-eat foods in eastern Nigeria. Int $J$ Food Microbiol. 1991, 12:275-279.

18. Wu S, Huang J, Wu Q, Zhang J, Zhang F, Yang X et al: Staphylococcus aureus Isolated From Retail Meat and Meat Products in China: Incidence, Antibiotic Resistance and Genetic Diversity. Front Microbiol. 2018 9: 2767.

19. Higenyi J, Kabasa JD: Microbial contamination load of hatching eggs in Butaleja, eastern Uganda. Anim Vet Sci. 2014 2: 22-30.

20. Igbinosa EO, Beshiru A, Akporehe LU, Oviasogie FE, Igbinosa OO: Prevalence of MethicillinResistant Staphylococcus aureus and Other Staphylococcus Species in Raw Meat Samples Intended for Human Consumption in Benin City, Nigeria: Implications for Public Health. Int J Environ Res Public Health. 2016 13(10): 949.

21. Wu S, Huang J, Zhang F, Wu Q, Zhang J, Pang R et al: Prevalence and characterization of food related methicillin resistant Staphylococcus aureus (MRSA) in China. Front Microbiol. 2019 10:1-13.

22. Ma Y, Zhao Y, Tang J, et al: Antimicrobial susceptibility and presence of resistance \& enterotoxins/enterotoxin-likes genes in Staphylococcus aureus from food. CyTA Journal of Food. 2018, 16(1): 76-84.

23. Chaalal W, Chaalal N, Bourafa N, et al: Characterization of Staphylococcus aureus isolated from food products in Western Algeria. Foodborne Pathog. Dis. 2018, 15: 353360.

24. Wang W, Baloch Z, Jiang $T$, et al: Enterotoxigenicity and antimicrobial resistance of Staphylococcus aureus isolated from retail food in China. Front. Microbiol. 2017, 8:2256.

25. Bhattacharyya D, Banerjee J, Bandyopadhyay S, et al: First report on vancomycin-resistant Staphylococcus in Bovine and Caprine milk. Microb Drug Resist. 2016, 22(8): 675-681.

26. Abd El-Aziz NK, Abd El-Hamid MI, Bendary $\mathrm{MM}$, et al: Existence of vancomycin resistance among methicillin resistant $S$ aurues recovered from animal and human sources in Egypt. Slov Vet Res. 2018, 55 (Suppl 20): 221-30.

27. Al-Amery K, Elhariri M, Elsayed A, et al: Vancomycin-resistant Staphyloocus aureus isolated from camel meat and slaughterhouse workers in Egypt. Antimicrob Resist Infect Control. 2019 5(8):129 